\title{
Positive emotions, positive feelings and health: A life philosophy
}

\author{
Carrie Lim Ching \\ The University of Hong Kong, Pok Fu Lam, Hong Kong \\ Vivian Li Chan \\ The University of Hong Kong, Pok Fu Lam, Hong Kong
}

\begin{abstract}
The paper was intended to explore the correlation between emotion and feeling. It has involved two phenomena referring to health. Positive emotions experienced by humans are not born spontaneously. Various good and pleasant things make us experience positive emotions. Those feelings make us enjoy life's moments. As reported by Psychology Today, feeling positive emotions makes us healthier physically and mentally. Feeling it with others will also foster trust and compassion. Positive emotions will also keep people from stress. happy feelings are the emotions most often talked about and known. However, there are a variety of other positive emotions that are nuances of feeling happy. In 2009, psychologist Barbara Frederickson in her book Positivity identified 10 other positive emotions that are universally felt by humans in addition to feeling happy.
\end{abstract}

Keywords---emotion, experience, feeling, happy, life.

\section{Introduction}

Finding delicious food in a new restaurant, or when you find a romantic scene in a movie that you watch. Joy is a signal that the situation is encouraging and encourages us to enjoy the situation that is happening. Thank You Feelings of gratitude arise when we find that someone has done something useful for us. We are grateful for the gifts we are given, the kindness we have received, and the time we have spent. Gratitude drives us to look for ways to repay the kindness and show our care for others. Proud When we reach a predetermined target or make an important contribution to a project, we feel proud of our abilities. Pride arises as a response to the success of getting what we want. Calm We feel calm and peaceful when in a stable state. According to Frederickson, calm makes us enjoy the present moment and re-evaluate our priorities. Feeling calm makes us understand deeply our own personal. Curious We feel curious when we find something new and we are interested in exploring it. 
Curiosity can trigger us to read many articles from our favorite topics or explore a foreign environment. Curiosity makes us eager to explore and learn to gain new insights. Excitement: finding fun is an emotion that is closely related to laughter. This arises when we find two ridiculous contrasts. A tingle to laugh also arises in situations that we did not anticipate before. Whatever makes us laugh, let alone laughs at others, will strengthen our bond with that person. Hope Hope is a positive emotion that arises when we imagine a better situation in the future. Hope makes us optimistic through difficult times. Although not infrequently the problems we face make us sad and worried, hope encourages us to try better and be tough in dealing with things that are not desired. Inspired When we see others trying their hardest and achieving what they want, we are inspired to emulate it.

Feeling inspired makes us appreciate the potential of others and encourages us to maximize our capacity and potential as well. Amazed Something that riveted will captivate us and bring a feeling of "being connected" to something bigger than ourselves. Extraordinarily beautiful things, like copper twilight in the vast savanna, can make us momentarily admire the beauty of the universe. Amazedness often changes the way we see the environment or even the world we live in now. Love is the most often talked about positive emotion. Frederickson defines love as a combination of the experiences we share with special people. The experience includes a variety of emotions mentioned above. The moments we experience with that person make us know each other better and care more about them. This is what gives birth to a healthy relationship and increasingly strengthens intimacy for couples.

\section{Method}

When viewed from the three realms commonly used in education, namely the cognitive, affective, and psychomotor domains, emotions are included in the affective domain. Emotions affect many other psychological functions, such as observation, response, though, and will. Individuals will be able to make observations or thoughts well if accompanied by good emotions too. This is what Daniel Goleman said in his book Emotional Intelligence, underlining that events that involve emotions will be embedded in memory faster and more deeply in the brain circuitry. Individuals will give a positive response to an object when accompanied by positive emotions as well. Conversely, individuals will make observations or negative responses to an object if accompanied by negative emotions towards the object.

\section{Definition of Emotions}

Many definitions of emotions expressed by experts because indeed the term emotion according to Daniel Goleman (1995) who is an expert on "emotional intelligence", the exact meaning is still very confusing, both among psychologists and philosophers in the period for more than a century. Because it is so confusing the meaning of emotions, Daniel Goleman (1995) in defining emotions refers to the most literal meaning taken from the "Oxford English Dictionary" which defines emotions as any activity or upheaval of thoughts, feelings, passions; every mental state that is great and overflowing. Furthermore, Daniel 
Goleman(1995) says that emotions refer to a specific feeling and thoughts, a biological and psychological state and a series of tendencies to act.

Meanwhile, Chaplin (1989) in the "Dictionary of Psychology" defines emotion as an aroused state of an organism including conscious changes, which are profound from behavioral change. Chaplin (1989) distinguishes emotions from feelings and he defines feelings (feelings) is a conscious experience that is activated both by external stimulants and by various physical states.

Thus, emotions are a response to a stimulus that causes physiological changes accompanied by strong feelings and usually contain the possibility to erupt. Such responses occur both to external and internal stimulants. With this definition the difference between emotions and feelings becomes clearer, even here it seems clear that feelings belong to emotions or become part of emotions. According to Daniel Goleman (1995), there are hundreds of emotions with various variations, mixtures, mutations, and nuances so that the meaning they contain is more, more complex, and more subtle than the words and definitions used to run emotions.

\section{Forms of Emotions}

Although emotions are so complex, Daniel Goleman(1995) had time to identify several groups of emotions, namely:

- Anger; in it includes violent, angry, hateful, angry, irritated, irritated, disturbed, bitter, angry, offended, hostile, violent, and pathological hatred.

- Sadness; in it include poignant, sad, gloomy, gloomy, melancholy, self-pity, loneliness, rejected, despair, and depression.

- Fear; in it include anxiety, fear, nervousness, worry, anxiety, feeling very scared, sad, alert, uneasy, horrified, wry, panicked, and phobic.

- Enjoyment; in it includes happy, happy, lightly satisfied, cheerful, happy, entertained, proud, sensual pleasure, amazed, fascinated, satisfied, fulfilled, excited, delighted, and mania.

- Love; it includes acceptance, friendship, trust, kindness, close feelings, devotion, respect, love and love.

- Surprised; in it includes gasping, amazed, and stunned.

- Annoyed; in it include contempt, disgust, nausea, nausea, hate, dislike, and want to vomit.

- Shame; it includes guilt, shame, heart, regret, contempt, disgrace, and broken heart.

From this list of emotions, based on Paul Ekman's research findings from the University of California in San Francisco, it turns out that there are emotions known by nations throughout the world, namely emotions that are manifested in the form of facial expressions which contain emotions of fear, anger, sadness, and pleasure. Facial expressions like that are recognized by nations throughout the world despite having different cultures, even including nations who are illiterate, not polluted by movies, and even television broadcasts. Thus, facial expressions as representations of emotions have a universality about these emotions. This conclusion was taken after Paul Ekmanconduct research by showing facial 
photographs depicting the above emotional expressions to people who have cultural remoteness, namely the Fore tribe in Papua New Guinea, a remote tribe of stone-age culture in an isolated highland. The result was that they all recognized the emotion that was pictured on the facial expressions in the photos.

\section{Discussion}

Basic themes in positive psychology include the relationship between positive emotional states and well being. Psychologists assume that if someone can get rid of their negative emotions then positive emotions will automatically take place (Compton, 2005). Seligman describes a pleasant life as a life that manages to seek positive emotions about the present, past and future (Seligman, 2002 in Linley \& Joseph, 2004). In the past, emotional researchers focused more on negative emotions such as fear, anger, anxiety, and sadness (Seligman and Csikszentmihalyi, 2000 in Compton, 2005). Negative emotions are stronger and attract more attention than positive emotions. Negative emotions are more often understood as the evolution of adaptation to the threats faced by our forefathers. Emotional tension is often manifested in fears or worries. These fears and worries depend on the extent of success or failure experienced in the struggle of the problem (Isen, 2003 in Compton, 2005).

Anxiety has been shown to narrow the range of thoughts and actions, while positive emotions produce cognitive states that are more conducive to mental flexibility and behavior (Losada, 1999) and the highest growth (Fredrickson, 2001). Seligman (2002) classifies positive emotions in three categories: those related to the past, present and future. Positive emotions related to the future include optimism, hope, confidence, faith, and trust. Satisfaction, contentment, fulfillment, pride, and serenity are the main positive emotions associated with the past. There are two different classes of positive emotions related to the present: momentary pleasures and enduring gratifications Emotional theories that have dominated psychology for most of their history have proven useful for studying negative emotions, but are often unsuitable for the study of positive emotions (Fredrickson, in Lewis, Haviland-Jones, \& Feldman Barrett, 2008).

In the past 10 years, positive emotions have come to their own. Awakening in positive emotion research comes from two sources: interest in the psychology of a good life (Ryff \& Singe; Fredrickson; Csikszentmihalyi \& Csikszentmihalyi in Lewis, Haviland-Jones, \& Barrett, 2008); and several research programs try to build an empirical model, namely bottom-up on positive emotions, rather than imposing on old models that have been built mainly for negative emotions (Lewis, Haviland-Jones, \& Barrett, 2008). Emotions are trends in multicomponent responses that are revealed over a relatively short period. Emotions begin with an individual's assessment of the personal meaning of some preliminary events called people's environmental relationships, or adaptational encounters (Lazarus in Snyder \& Shane, 2002). Emotions involve judgments of inner thoughts, feelings, and memories, sometimes combined with assessments of the environment and physiological changes, most often involving behavioral responses (Kleinginna and Kleinginna in Ghorman, 2004). 
Emotions according to Goleman (2001) are basically an impulse to act, an instant plan to tackle problems that have been instilled gradually by evolution. The root of the word emotion is more, the verb in Latin is moving or moving. The tendency to move is absolute in emotions. Emotion provokes action, emotions become the root of the urge to act separately from the reactions that appear in the eye. Emotions begin with an individual's assessment of the personal meaning of some of the previous events referred to by Lazarus (1991) as "person-environment relations" or "adaptational encounters." Whether consciously or unconsciously, this assessment process triggers the fall of responses incorporating mental, physical, and subjective changes (Lewis, Haviland-Jones, \& Barrett, 2008).

There is no universal definition of positive emotions. Positive emotions are a complex construction that has many synonyms including positive, happiness, optimism and subjective well-being. Positive emotions include not only pleasant emotions (joy, context, interest, and love), but also cognition (that is, interpretations of certain life events or circumstances), and certain actions or behaviors (that is, sports, presenting beauty, expressing gratitude) which promotes health and well-being. Positive emotions reflect an individual's relationship with his environment, how to experience and find meaning in life. Positive emotions are relatively stable over time but can change in response to direct situations (ie, promotions, divorce, etc.). Similarly, certain intentional actions, such as identifying things in life, one of which is being grateful, has been shown to increase positive emotions. Conversely, focusing on the negative aspects of certain situations has been shown to reduce positive emotions.

Regarding negative emotions, positive emotions have received little empirical attention. There are several, interrelated reasons for this. One of them, which has plagued psychology in general, is the traditional focus on psychological problems along with remedies for those problems. Negative emotions when extreme, prolonged, or inappropriate contextual produce many serious problems, ranging from phobias and anxiety disorders, aggression and violence, depression and suicide, eating disorders and sexual dysfunction, to several physical disorders related to stress. The overall balance of positive and negative emotions of the community has been shown to contribute to their subjective well-being (Diener et al., 2002).

Positive emotions also produce optimal functions, not only in the present, pleasant times but also in the long run (Fredrickson, 1998). Based on the above definition it can be concluded that positive emotions are mental states that have elements of feelings, senses, thoughts, and actions that can produce positive effects, such as cheerfulness, peace, satisfaction, and happiness. Types of Positive Emotions Positive emotions are subjective feelings that are pleasant and can include physiological changes and require the assessment of some stimulus or assessment of its meaning (Fredrickson and Cohn, 2008). Fredrickson (Compton, 2005) divides positive emotions into four types, namely joy (happiness), interest (interest), contentment (satisfaction), and love (love). a) Joy (Pleasure) Fredrickson describes Joy in the form of creating a desire to play, pushing boundaries, and being creative, urgently clear not only in social and physical behavior but also in intellectual and artistic behavior (Hefferon \& Boniwell, 2011). b) Interest (Interest) Interest is a positive emotion phenomenologically different, creates an urge to 
explore, receive new information and experience, and expand themselves in the process. (Fredrickson in Hefferon \& Boniwell, 2011) According to Fredrickson (Compton, 2005) interest or interest always has motivation in what is done. Interest plays an important role in exploring and increasing knowledge. Interest can be a feeling of curiosity (curiosity), intrigue, excitement (passion/enthusiasm), wonder (a sense of wonder), and intrinsic motivation (intrinsic motivation). Interest as an outcome that supports the interest in exploration also builds a store of individual knowledge and abilities. c) Contentment can create the urge to sit back and enjoy the current state of life and integrate this state into a new view of self and the world (Fredrickson in Hefferon \& Boniwell, 2011). Contentment is related to one's feelings towards the world and a more integrated view of self and the world. Contentment relates to an awareness of motions that includes selfawareness and openness to experience. Contentment is usually identified with feelings of calm (Compton, 2005) d) Love According to Fredrickson (Hefferon \& Boniwell, 2011) love is a mixture of different positive emotions (for example, joy, interest, and satisfaction) experienced in a safe context, close relationships creating an iterative cycle of the urge to play together, explore, and enjoy the people we love. Boarden and Build Theory Boarden and Build (expand-and-build) are a multi-model, which offers a comprehensive explanation for the observed effects of positive emotions. This theory has two modules, called boarden (expand) and build (build). But the module itself is composite. The boarden's theory draws together direct findings, the temporary effects of positive emotions in the areas of physiology, attention, motivation, and analytical and social cognition, by suggesting that they all share ideas about broadening.

The build theory draws together findings of the beneficial effects of frequent, prolonged positive emotions on work success, relationships, mental health, physical health, development, and life satisfaction, by ensuring that all these results are obtained from an expanded state (boardened). This shows that boarden and build theory seeks to connect three different levels of phenomena, namely subjective positive emotions, temporary states of cognition/attention/motivation, and long-term life outcomes. The totality of work done on the theory can be explained by two hypotheses for each module. The model, which provides a rubric to tie together various phenomena, and a hypothesis, which proposes a relationship between two different levels. The broaden model is a unipolar axis of "breadth" that can be applied to many domains of function, including physiology, perception, attention, motivation, cognition, and social cognition. The low breadth illustrates an exclusive focus on important, essential, or direct information. "Expanding" or high breadth represents an increase in attention to information devices, overall processing strategies, and long-term results. The broaden hypothesis is experiencing a positive emotion that leads to a temporary expansion in many or all applicable fields. The Build Model is the number of functions that can be conceptualized as personal resources, which are built up over time and which contribute to survival and develop when threats or opportunities arise. Such resources include psychological resources, such as self-efficacy and coping skills; cognitive resources, such as reasoning abilities and special knowledge in certain domains; physical resources, such as effective immune function and proper stress regulation; and relational resources, such as intimate relationships and broad social networks. The Build Hypothesis is that the more often someone experiences 
positive emotions, the level of their personal resources tends to be higher. This is because people tend to build more resources when in an expanded state. According to Fredrickson (Compton, 2005), positive emotions emerge to expand the meaning of momentary thought-action and build lasting personal resources. The broaden and build theory describes the form of positive emotions in terms of expanding thinking-action that can be done and explain their function in terms of building personal enduring resources. Fredrickson's positive emotions laboratory has repeatedly tested the expanding effects of positive emotions. They propose that when we experience one of the main positive emotions, our mind tends to open or expand and we can think outside the box. This is important because when we expand our thinking patterns, we tend to get a bird's-eye view of our situation, which can help produce alternative solutions for the task at hand. We also become more creative with positive emotions found to enhance the task of verbal creativity (Hefferon \& Boniwell, 2011).

Positive emotions don't only open our minds to alternative strategies. Research has shown that the experience of positive emotions coupled with the effects of expansion can build personal resources, which we can enter when needed. This includes intellectual resources (problem-solving, open to learning), physical resources (heart health, coordination), social resources (we can maintain relationships and make new ones) and psychological resources (resilience, optimism, sense of identity and orientation purpose). As this thing develops, they encourage more positive emotions that continue to build resources that move upward spiraling. The Boarden and Build theory shows that everyday experiences of entertainment, joy, love, and curiosity are a fundamental part of how we function. They exist because they make the individuals who experience them become more successful human beings. We have the choice to take time for these emotions, awaken them, and enjoy them in our daily lives, and when we do we create space for ourselves to learn, reflect on, and grow. People whose lives don't seem inherently positive can benefit from finding a source of happiness (Aknin et al., 2018; Burgdorf \& Panksepp, 2006).

What is the meaning of emotions scientifically? Psychology is the most intensive and extensive branch of science in researching emotions. However, even among the most brilliant researchers, there is no similarity of opinion about the meaning of emotions. There are at least 92 different definitions of emotions. This explains that emotion is a very complex phenomenon. However, everything remains a common thread. Well, there are five common threads between definitions of emotion, namely emotions triggered by one's interpretation of an event, a strong physiological reaction, emotional expression based on genetic mechanisms, is information from one person to another, and helps someone adapt to changing environmental situations (Mesquita \& Walker, 2003; Gilbert et al., 2013).

Emotion is triggered by the interpretation of an event. The emotional process begins when you give personal meaning to some antecedent events. The same situation will not necessarily produce the same emotions because it depends on the meaning of the situation. Let's say your friend cheats on you. If you judge it normally, then maybe you don't experience emotions. But if you judge it against the values of friendship and harm you, then you start to be disappointed with it. Strong physiological reaction. Emotions arise with enough physiological reactions 
to make you aware of differences in yourself. For example, rapid heartbeat, trembling hands, want to run away, and so on.

His emotional expression is based on genetic mechanisms. That is, all people have similarities in expressing emotions. Sad facial expressions in Scandinavians, very similar to sad facial expressions in Papuans. Likewise, the expression on the happy face of the Arabs is similar to the happy expressions of the Javanese. Emotions are information from one person to another. Through emotion, someone conveys intentions on others. Fear experienced by someone as information that he does not want to do something. Anger experienced is information that he does not like to be treated like the treatment he has received. In short, through emotions, we know what has happened.

Emotions help adapt to changing environmental situations. Imagine if humans do not feel afraid to plunge into the abyss. So, maybe human death is a common thing. Because of fear, then humans try to work around the abyss, maybe make a bridge, make a fence, or stay away. The emergence of emotions is usually spontaneous, unconscious and without intention. Suddenly you experience certain emotions. You only realize experiencing an emotion after the emotion that you experience. For example, you meet a stranger, then spontaneously you experience emotions. You cannot intend to experience certain emotions. You cannot intend to be afraid when going to the forest. So until here, can you conclude what is meant by emotion?

The human mind or cognitive includes work such as categorization, remembering, analyzing, interpreting, evaluating and others. The core purpose of cognitive work is to understand everything about the environment and oneself. Therefore emotions and thoughts (cognition) are closely related and inseparable.

Emotions arise after going through the interpretation of an event. Nevertheless, the cognitive processes that give birth to emotions cannot always be realized. For example angry. Before getting angry, then there is an assessment that you did before. It could be that you judge that you've been lied to, someone else doesn't act the way you want, the situation doesn't happen the way you want it or the others that bother you. After the assessment, then you are angry. Even when angry, you still do cognitive work. For example, if what doesn't satisfy you is your boss, then you might not show your anger. Meanwhile, if the unsatisfactory are weaker than you, then maybe you dare to curse them. While angry, you might also think of taking revenge, assessing the reasons for someone unsatisfactory, or something else. That is, the mind always works before and during emotions.

The same situation will not necessarily produce the same emotions because it depends on the meaning of the situation. For example when you face a large bear in the forest, if you interpret that the bear is threatening you, then you might be scared. But if you interpret that the bear is just an ordinary harmless animal, then you will not be afraid. Likewise, when you are left dead by a friend. If you judge it as a big loss, then you are very sad. Conversely, if you judge only deaths that naturally occur. You might not be sad. It might even be a relief that your friend has suffered from chronic pain. 
The part of the brain responsible for emotions is the part called the limbic system. The brain structures that play a role are the hippocampus, cingulate gyrus, rhinal cortex, amygdala, and orbitofrontal cortex. That's where emotions are regulated. Starting from receiving information about the situation, giving rise to certain feelings, to arouse physiological reactions.

Jaak Pankseep, a leading emotion researcher, suggests the flow of emotional commands in the brain. The flow of emotional commands has two kinds of simultaneous ways, namely communication on several brain structures and performing the function of responding to situations that pose challenges (consisting of 7 things, which can arouse hope, anger, fear, sexual urges, protection, panic or separation, and games or dominance). Both of them convey information from the sensory organs (sight, listener, smell, taste, touch), association cortex, and from memory to the limbic system and other parts of the nervous system. As a result, individuals will behave integrally and adaptively. If angry, it will show an angry expression. It will not happen when angry instead shows a happy expression.

The experts who pursue the field of psychoanalysis believe that emotions are a representation of the unconscious. Emotion or affect in terms of psychoanalysis is a mechanism that controls all aspects of human behavior. Emotions are believed to be very closely related to impulses or motives. To achieve security and survival, a person is born with the capacity to feel anxious. For breeding, a person is born with the capacity to feel sexual desire and affection. To avoid hopeless situations, a person is born with the capacity to feel depressed and withdrawn. In short, emotions are the way how a human's needs are met. The need to be protected, safe, powerful, controlling, interested, and self-autonomy is fulfilled through the emotions that arise. For example, the need for power gives rise to a sense of arrogance and pride when it comes to power. If not yet in power, a sense of anxiety arises or is threatened by those in power, who therefore push to become in power (Yoo \& MacInnis, 2005; Quoidbach et al., 2010).

Human motivational systems are believed to show themselves through emotions. When an emotion arises, it is a sign that certain motivations become active at that time. For example, you feel hungry, well when you find food, certain emotions emerge that indicate accessibility to that food. If the food smells and has a lot of disgust, you may feel disgusted so you don't want to eat it. If the food is eaten, emotion comes with relief. Likewise when you meet other types of friends. If you feel interested then you will approach him to ask him out. If you don't feel interested then you might not ask her out.

You may not be aware of your impulses, motives or motivations in a moment. However, these things affect your emotions. Why do the emotions of love appear to the opposite sex that is of interest? It is because you have a sexual drive towards the opposite sex. You might not realize that. As for what you realize is that you just want to meet. Emotion itself is the main motivator of humans in living life. Humans always try to maximize pleasant emotions and minimize unpleasant emotions. Almost all activities carried out by humans in that framework. Although of course, it doesn't always work. But surely, that is what everyone is doing. People work is in order to get more pleasant emotions. People 
expect to be happier if they succeed in doing it (Bono \& Ilies, 2006; Mikolajczak et al., 2007).

What is your nature? If you mention anger or calm, then you have shown the emotional state as a personality trait. That is, if an emotion tends to be repeated in high intensity, then the emotion is considered a personality trait. People who are often angry will be called having an angry nature. People who often experience fear will be called timid. People who often show pride will be called arrogant. People who are often sad will be called moody (Kashdan \& Breen, 2008; Jabbi et al., 2007). Anxious people are called worries.

The personality traits that take the form of extreme or extreme exaggeration will be referred to as personality disorders. For example, very timid people may be diagnosed as a dependent personality type. Then people who are very hottempered and very irritable will be called antisocial personalities. According to psychoanalysts, narcissistic personalities, i.e., personalities who worship themselves, are caused by a conflict between the desire to feel safe and the desire to do something risky. On the one hand crave safe emotions, on the other hand, wants to do something that has the potential to cause insecurity. Narcissists tend to have a certain feeling for everything and feel perfect as a defensive reaction or unsatisfactory event (Heuven et al., 2006; Evers et al., 2013).

Emotion has vital functions for humans. Emotions experienced by humans make humans able to cause responses based on the information they receive. For example, if someone bothers you, then you get angry. Then out of anger, someone might act to chase away the intruder. In general, there are at least 7 emotional functions for humans (Strohminger et al., 2011; Kwortnik Jr \& Ross Jr 2007). Each function plays an important role in human survival because it helps in adjusting to the environment.

- Cause an automatic response in preparation for a crisis. Imagine you suddenly meet a snake. You might feel surprised and then jump. Because of that surprise, you survived the snake bite. Suddenly you jump. Imagine also when you meet a tiger in the forest because you are afraid then you run away. Without thinking, you just run away. That is, a state of crisis can be bypassed because you have an automatic response. You automatically respond to snakes by jumping and respond to tigers by running. Also, imagine that you were scolded by your boss because your work went wrong. You feel scared. If you don't finish, you will be fired. Because of that fear, you try to get the job done.

- Adjust the reaction to special conditions. When you are abandoned by someone you care about, you will be sad. Well, the existence of sadness makes you adjust to the right reaction to the conditions of loss. Then, for example, you are sailing in the ocean by ship. At that time there was a big storm crashing. Your ship is shaken to and fro. It may be that because of emotional anxiety, you become more alert. You then use afloat, hold on tight, or take other security measures.

- Motivating actions aimed at achieving certain goals. Certain emotions encourage someone to take certain actions. For example when experiencing emotions of love. Because of that emotion, you do things to 
attract the attention of your loved one. You are willing to go through heavy rain because you want to show that you always keep your promises. Maybe you are also willing to accompany him to climb the mountain, even though you are afraid of heights.

- Communicating an intention to others. You are angry. What is your message? You might suggest that you don't want to be overlooked. Maybe you gave the message that you want to hit people who make you angry. Maybe you also advised taking revenge on him. In essence, there is a message behind your emotions.

- Increase social ties. What happens if your social relationships with other people without emotions? The relationship was bland. There will be no sense of closeness that is awakened. The existence of positive emotions such as happiness, acceptance, affection, joy, peace, will make existing social relationships more closely. You get closer to your friends because of the positive emotions that are continually stronger in the relationship.

- Influences memory and evaluation of an event. Dono meets a virgin named Evi. Her face is beautiful. They are acquainted. After getting acquainted, the emotions experienced by Dono and Evi during a date will be a benchmark if the date will be remembered strongly, or forgotten. If both Dono and Evi feel strong emotions, they may go on to the next date. If they don't feel anything, they might forget each other.

- Improve memory of certain memories. Someone will remember more memories that are filled with strong emotions. For example, the first time a boyfriend kissed because at that time you like hovering in the clouds. Then for example when you are left dead your parents. You remember it strongly because at that time you felt extreme sadness. Likewise, when you remember the times when you felt very scared. For example threatened thugs, attacked by dogs, or others.

\section{Conclusion}

Emotions and feelings (emotion \& feeling). Both are used overlapping in everyday conversation. When someone asks others what they feel when betrayed by their girlfriend, rarely do people ask, "how are your emotions?", Most will ask, "how do you feel?" In everyday language, the word emotion is very rarely used. The word feeling is far more commonly used. Feelings contain the existence of subjective experience. What is felt by one person to another is relatively difficult to compare. Only the self can experience the feelings that arise. Therefore it is called subjective experience. For example, you feel at peace, then you can experience it. The sense of peace that is felt by others can be different levels.

Most people think that emotions are one type of feeling. Something is considered an emotion when someone feels certain feelings, especially anger. Besides being angry, other feelings that are often regarded as emotions include love, sadness, happiness, and jealousy. People will say Andi is emotional when he is angry (he is 'emotional' because he was betrayed by his girlfriend), but also when he is very happy (he is so 'emotional' to meet his mother), sad (he is so 'emotional' at his father's funeral ), jealous (he 'emotion' knows his girlfriend has dinner with someone else), or love (his emotions are so deep in his lover). Some experts say that emotions contain feelings. This means feelings are a component of emotions. 
The feeling is defined as a condition that is felt to be happening within a person. You experience feelings of anger because you feel something flaring up within you. Emotion occurs only when someone feels something happening in him.

So, what's the difference between feelings and emotions? Both are relatively the same. In fact, according to an emotion researcher from Australian National University, namely Anna Wierzbicka, not all cultures have the word for emotions as they are conceptualized in English while words that mean feelings are in all languages. According to him again, the word emotion is preferred because it feels more objective and more scientific than the word feeling. Therefore the word emotion is much more widely used in the world of science. What about hunger from lack of food, thirst for lack of drinking, burning sensation from the hot sun, sweet taste of sugar, bitter taste of coffee, and bone pain? Of course, it does not include the category of feelings associated with emotions. Feelings that are interpreted as emotions are feelings that are not related to what is felt physically. There is hunger, but there is no hunger emotion. There is a burning sensation but no hot emotions. There is a sweet sugar taste but no sweet emotions. Emotions are feelings related to mood.

\section{References}

Aknin, L. B., Van de Vondervoort, J. W., \& Hamlin, J. K. (2018). Positive feelings reward and promote prosocial behavior. Current opinion in psychology, 20, 5559. https://doi.org/10.1016/j.copsyc.2017.08.017

Bono, J. E., \& Ilies, R. (2006). Charisma, positive emotions and mood contagion. The Leadership Quarterly, 17(4), 317-334. https:/ / doi.org/10.1016/j.leaqua.2006.04.008

Burgdorf, J., \& Panksepp, J. (2006). The neurobiology of positive emotions. Neuroscience \& Biobehavioral Reviews, 30(2), 173-187. https://doi.org/10.1016/j.neubiorev.2005.06.001

Chaplin, J. P., \& Kartono, K. (1989). Kamus lengkap psikologi. Rajawali Pers.

Compton, W. C. (2005). Introduction to Positive Psychology. Thomson Wadsworth.

Diener, E., Lucas, R. E., \& Oishi, S. (2002). Subjective well-being: The science of happiness and life satisfaction. Handbook of positive psychology, 2, 63-73.

Evers, C., Adriaanse, M., de Ridder, D. T., \& de Witt Huberts, J. C. (2013). Good mood food. Positive emotion as a neglected trigger for food intake. Appetite, 68, 1-7. https://doi.org/10.1016/j.appet.2013.04.007

Fredrickson, B. L. (1998). Cultivated emotions: Parental socialization of positive emotions and self-conscious emotions. Psychological Inquiry, 9(4), 279-281. https:/ /doi.org/10.1207/s15327965pli0904_4

Fredrickson, B. L. (2001). The role of positive emotions in positive psychology: The broaden-and-build theory of positive emotions. American psychologist, 56(3), 218. https://psycnet.apa.org/doi/10.1037/0003-066X.56.3.218

Fredrickson, B. L. (2001). The role of positive emotions in positive psychology: The broaden-and-build theory of positive emotions. American psychologist, 56(3), 218.

Fredrickson, B. L., Cohn, M. A., Coffey, K. A., Pek, J., \& Finkel, S. M. (2008). Open hearts build lives: positive emotions, induced through loving-kindness meditation, build consequential personal resources. Journal of personality and social psychology, 95(5), 1045. 
Gilbert, K. E., Nolen-Hoeksema, S., \& Gruber, J. (2013). Positive emotion dysregulation across mood disorders: How amplifying versus dampening predicts emotional reactivity and illness course. Behaviour research and therapy, 51(11), 736-741. https://doi.org/10.1016/j.brat.2013.08.004

Goleman, D. (2001). An EI-based theory of performance. The emotionally intelligent workplace: How to select for, measure, and improve emotional intelligence in individuals, groups, and organizations, 1, 27-44.

Goleman, D. (2006). Emotional intelligence. Bantam.

Hefferon, K., \& Boniwell, I. (2011). Positive psychology: Theory, research and applications. McGraw-Hill Education (UK).

Heuven, E., Bakker, A. B., Schaufeli, W. B., \& Huisman, N. (2006). The role of self-efficacy in performing emotion work. Journal of Vocational Behavior, 69(2), 222-235. https://doi.org/10.1016/j.jvb.2006.03.002

Horman, G. (2004). U.S. Patent Application No. 10/403,883.

Isen, A. M. (2003). Positive affect as a source of human strength.

Jabbi, M., Swart, M., \& Keysers, C. (2007). Empathy for positive and negative emotions in the gustatory cortex. Neuroimage, 34(4), 1744-1753. https://doi.org/10.1016/j.neuroimage.2006.10.032

Kashdan, T. B., \& Breen, W. E. (2008). Social anxiety and positive emotions: A prospective examination of a self-regulatory model with tendencies to suppress or express emotions as a moderating variable. Behavior Therapy, 39(1), 1-12. https://doi.org/10.1016/j.beth.2007.02.003

Kleinginna, P. R., \& Kleinginna, A. M. (1981). A categorized list of emotion definitions, with suggestions for a consensual definition. Motivation and emotion, 5(4), 345-379.

Kwortnik Jr, R. J., \& Ross Jr, W. T. (2007). The role of positive emotions in experiential decisions. International Journal of Research in Marketing, 24(4), 324-335. https://doi.org/10.1016/j.ijresmar.2007.09.002

Lazarus, R. S. (1991). Cognition and motivation in emotion. American psychologist, 46(4), 352.

Lewis, M., Haviland-Jones, J. M., \& Barrett, L. F. (Eds.). (2010). Handbook of emotions. Guilford Press.

Linley, P. A., \& Joseph, S. (2004). Positive change following trauma and adversity: A review. Journal of traumatic stress: official publication of the international society for traumatic stress studies, 17(1), 11-21.

Mesquita, B., \& Walker, R. (2003). Cultural differences in emotions: A context for interpreting emotional experiences. Behaviour research and therapy, 41(7), 777-793. https://doi.org/10.1016/S0005-7967(02)00189-4

Mikolajczak, M., Menil, C., \& Luminet, O. (2007). Explaining the protective effect of trait emotional intelligence regarding occupational stress: Exploration of emotional labour processes. Journal of Research in personality, 41(5), 11071117. https://doi.org/10.1016/j.jrp.2007.01.003

Quoidbach, J., Berry, E. V., Hansenne, M., \& Mikolajczak, M. (2010). Positive emotion regulation and well-being: Comparing the impact of eight savoring and dampening strategies. Personality and individual differences, 49(5), 368-373. https://doi.org/10.1016/j.paid.2010.03.048

Seligman, M. E. (2002). Positive psychology, positive prevention, and positive therapy. Handbook of positive psychology, 2(2002), 3-12.

Seligman, M. E., \& Csikszentmihalyi, M. (2000). Positive psychology: An introduction (Vol. 55, No. 1, p. 5). American Psychological Association. 
Snyder, C. R., \& Lopez, S. J. (2002). The future of positive psychology. Handbook of positive psychology, 751-767.

Strohminger, N., Lewis, R. L., \& Meyer, D. E. (2011). Divergent effects of different positive emotions on moral judgment. Cognition, 119(2), 295-300. https://doi.org/10.1016/j.cognition.2010.12.012

Yoo, C., \& MacInnis, D. (2005). The brand attitude formation process of emotional and informational ads. Journal of Business Research, 58(10), 1397-1406. https://doi.org/10.1016/j.jbusres.2005.03.011 